\title{
ISOUEMIC CEREBROVASCULAR DISEASE RISK CHARTS FOR SPANISH POPULATION
}

\section{| Hospital \\ Clínico \\ Universitario \\ Lozano Blesa}

\begin{abstract}
M. Marín Gracia' ${ }^{1}$ A. Marín Ibañez², C. Tejero Juste ${ }^{1}$, A. López Bravo ${ }^{1}$, C. Pérez Lázaro1
\end{abstract}
${ }^{1}$ Hospital Clínico Universitario "Lozano Blesa, Neurology, Zaragoza, Spain;

${ }^{2}$ San José Primary Care Centre, Family Medicine, Zaragoza, Spain

\section{INTRODUCTION}

Atherothrombotic ischemic stroke is one of the mean causes of morbidity and mortality in Spain, leading to an important socio-sanitary cost. Although risk factors are well established, there are no specific risk charts for daily use in our work environment for primary prevention.

\section{OBJECTIVE}

To elaborate a predictive algorithm and a risk chart based on the major cardiovascular risk factors.

\section{PATIENTS AND METHOD}

A 5-year follow-up, prospective and analytic cohort study was done, including a primary care population (1924 men and 2498 women over 40 years) who accomplished the inclusion criteria. By logistic regression, a predictive equation and a risk chart were designed.

\section{RESULTS AND DISCUSSION}

The main risk factors within the studied population were age, smoking and atherogenic index. Blood pressure and diabetes were no significant likely owing to the fact that atherogenic index explained part of their variance, existing a correlation between them. The likelihood of ischemic atherothromotic stroke was explained with a $98,3 \%$ of probability by the following equation:

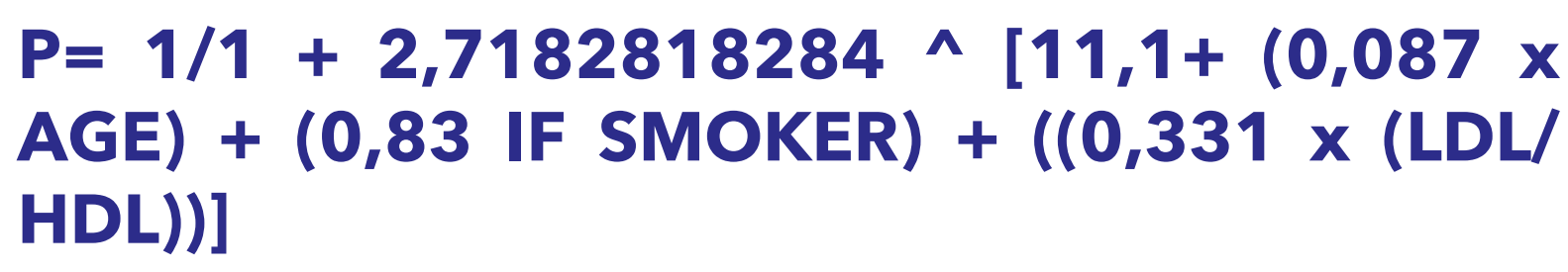
HDL))]

\section{CONCLUSION}

A tool for decision-making is presented, preferably by means of cholesterol management, once the rest of the factors are under control, in order to ameliorate the incidence of stroke. It is required to carry on with this line of research so as to achieve more predictive variables.

KEYWORDS: Cerebrovascular disease. Incidence. Prevalence. Ischemic cerebrovascular disease. Transient ischemic attack. Cardiovascular risk factors. Spanish population.

NON SMOKERS
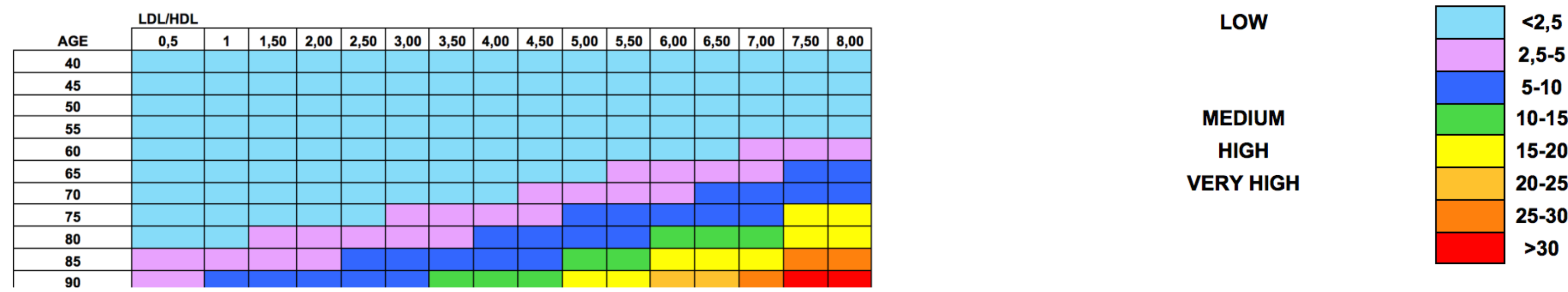

SMOKERS

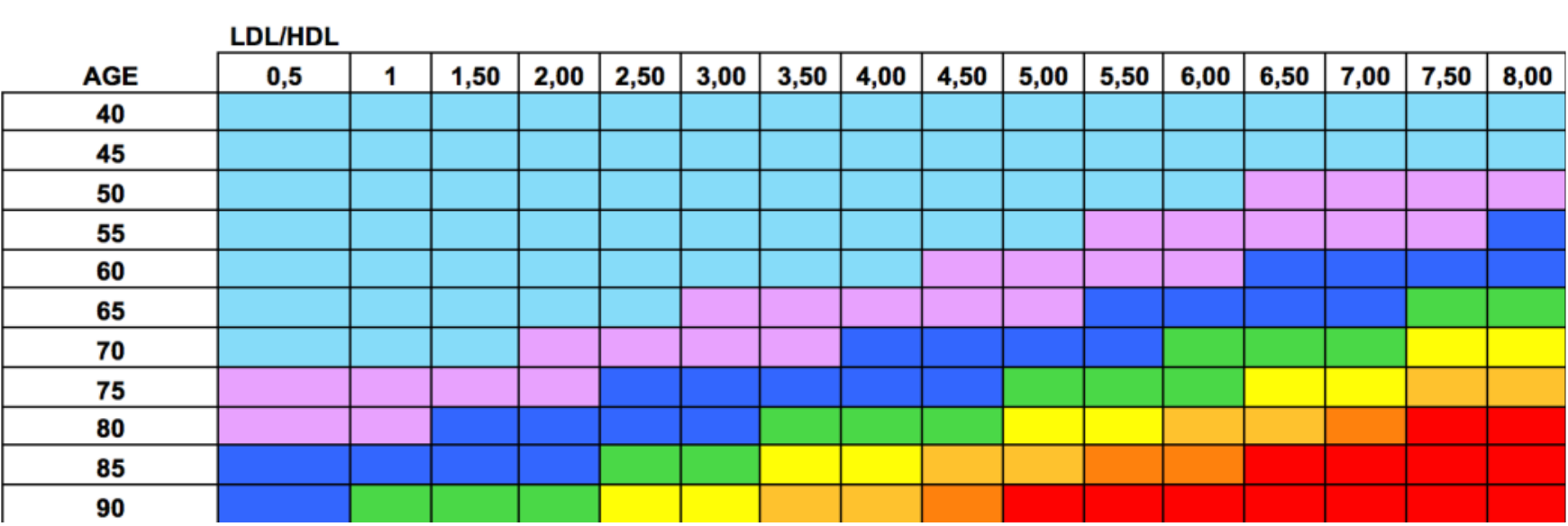

